\title{
Eccrine Poroma of the Postauricular Area
}

\author{
Hyun Rok Lee ${ }^{1}$, \\ Gyu Yong Jung ${ }^{1}$, \\ Hea Kyeong Shin ${ }^{1}$, \\ Dong Lark Lee ${ }^{1}$, \\ Jong Im Lee ${ }^{2}$, \\ Jung Hwan Kim ${ }^{1}$ \\ Departments of ${ }^{1}$ Plastic and Reconstructive \\ Surgery and ${ }^{2}$ Pathology, Dongguk University \\ College of Medicine, Gyeongju, Korea
}

No potential conflict of interest relevant to this article was reported.

\begin{abstract}
Eccrine poroma is a common benign cutaneous tumor that originates in an intraepidermal eccrine duct. This tumor exhibits acral distribution (sole, palm), and is rarely encountered in the head and neck area. In fact eccrine poroma in the postauricular area has only been rarely reported. A 55-year-old female visited our hospital with a main complaint of a mass that first developed in the left postauricular area about a year previously. The mass was painless, soft, protruding, domed, and dark red in color, and had slowly enlarged (at presentation it measured $1 \times 1 \mathrm{~cm}$ ). Excisional biopsy was performed. Histological examination showed distinct features, and eccrine poroma was diagnosed. Follow-up at 6 months postoperatively showed no recurrence. The frequency of eccrine poroma is dependent on eccrine sweat glands density, and thus, usually occurs on the palms or soles. For eccrine poroma in the head and neck region, the differential diagnosis must rule out other masses, such as nevus, skin tag, pyogenic granuloma, cyst, basal cell carcinoma, and seborrheic keratosis. Importantly, $18 \%$ of poromas show malignant transformation, and can develop into porocarcinoma. For these reasons, an eccrine poroma in the facial area requires histological examination, complete excision, and follow-up.
\end{abstract}

Keywords: Poroma / Ear

\section{INTRODUCTION}

Eccrine poroma is a common benign cutaneous tumor that originates in an intraepidermal eccrine duct. This tumor mostly occurs in middle-aged or older adults, and is equally likely in both genders. Usually eccrine poroma exhibits acral distribution (sole, palm), and is rarely encountered in the head and neck area. In fact, eccrine poroma in the postauricular area has only been rarely reported [1]. We report a case of eccrine poroma in the postauricular area.

\section{CASE REPORT}

A 55-year-old female visited our hospital with a main complaint of a mass that first developed in the left postauricular area about a

Correspondence: Gyu Yong Jung

Department of Plastic and Reconstructive Surgery, Dongguk University College of

Medicine, 87 Dongdae-ro, Gyeongju 38067, Korea

E-mail: jnjbeauty@naver.com

Received December 20, 2016 / Revised February 16, 2017 / Accepted February 16, 2017 year previously. The mass was a solitary, asymptomatic, $1.0 \times 1.0$ $\mathrm{cm}$ sized, brownish, protruding, soft nodule with central dark crust (Fig. 1), and had slowly enlarged. There was no history of trauma or infection. Atypical nevus and pyogenic granuloma were considered as differential diagnoses, and an excisional biopsy was performed under local anesthesia.

Histopathologic findings revealed that the tumor arose within the lower portion of the epidermis and extended downward into the dermis as broad anastomosing bands (Fig. 2A). Tumor cells had a uniform cuboidal appearance with a round basophilic nucleus (Fig. 2B). Follow-up at 6 months postoperatively showed no recurrence.

\section{DISCUSSION}

Eccrine poroma is a benign tumor that originates from the apical portion of an eccrine sweat gland. The frequency of eccrine poroma is dependent on eccrine sweat glands density, and thus, usually occurs on the palms or soles. However, eccrine poroma can de- 


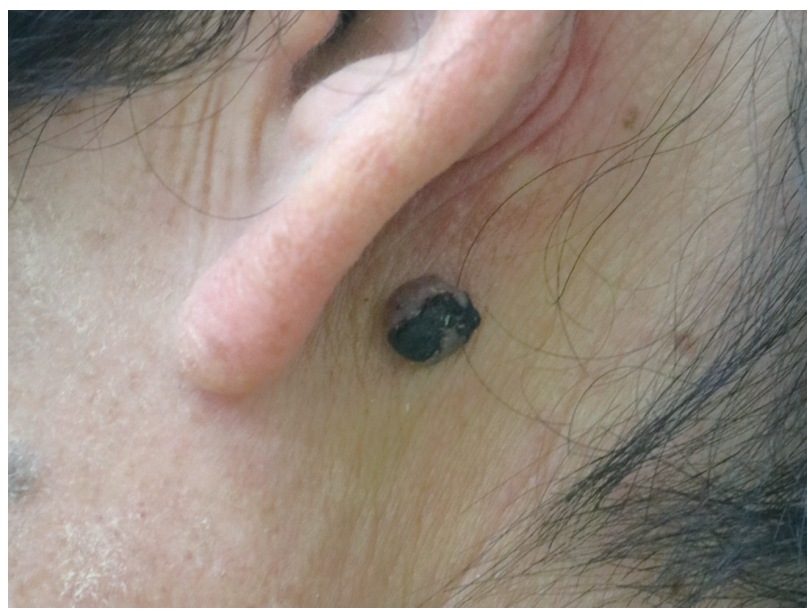

Fig. 1. Photograph showing a solitary, asymptomatic, $1.0 \times 1.0 \mathrm{~cm}$ sized, brownish, protruding, soft nodule with central dark crust.
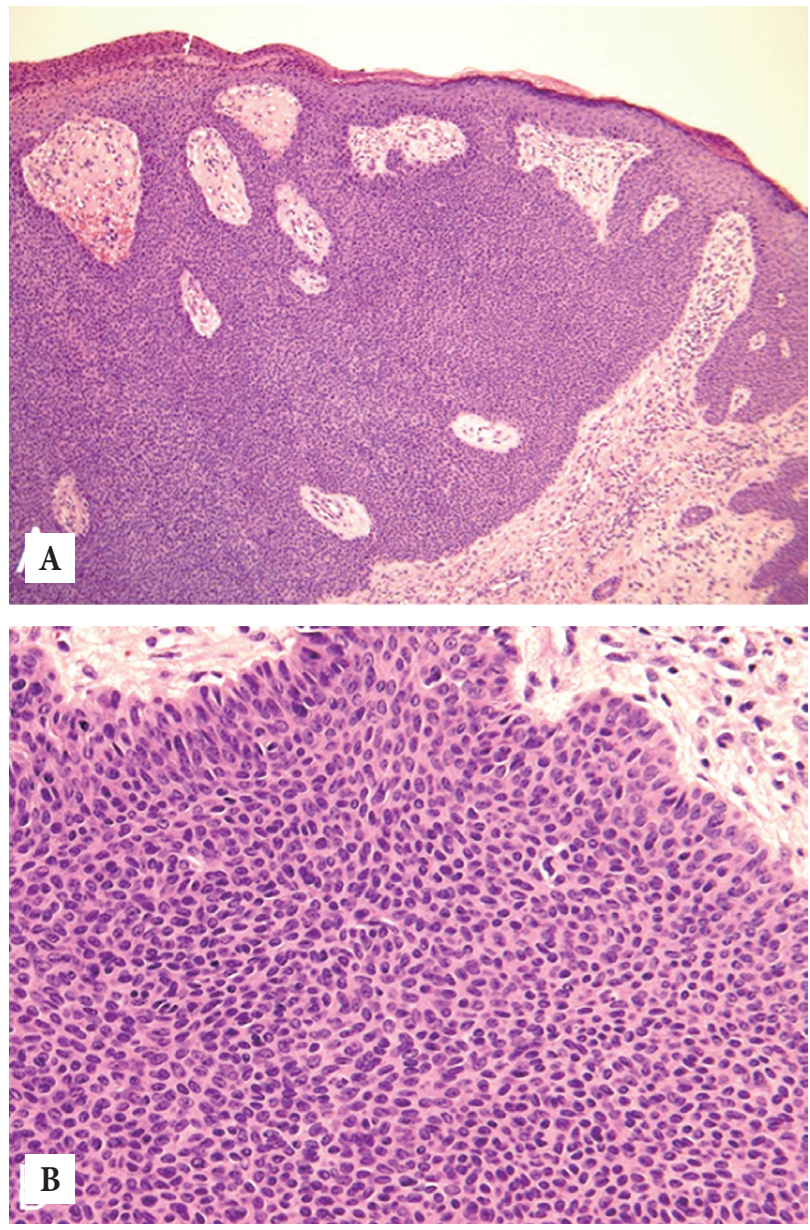

Fig. 2. Microscopic findings. (A) The tumor arose within the lower portion of the epidermis and extended downward into the dermis as broad anastomosing bands (H\&E, $\times 40$ ). (B) Tumor cells had uniform cuboidal appearance with a round basophilic nucleus $(\mathrm{H} \& \mathrm{E}, \times 200)$. velop in any part of the body with these glands [1].

Moore et al. [2] compared 10 cases of eccrine poroma in the head and neck with 10 cases with eccrine poroma in an extremity. They reported that eccrine poroma in the extremities was more likely to be pigmented, as was observed in the present case. Furthermore, they also reported that three cases of eccrine poroma in the extremities exhibited discharge and bleeding, caused pain, and showed a rapid growth pattern, whereas in our patient, eccrine poroma in the postauricular area did not display these symptoms

Goldman et al. [3] reported that the most common location for eccrine poroma is the foot, followed by the hand (reported prevalences were $65 \%$ and $10 \%$, respectively), and Hyman and Brownstein [4] reported $68 \%$ of eccrine poromas occur in feet, and that the remainder occur in various locations.

For eccrine poroma in the head and neck region, the differential diagnosis must rule out other masses, such as fibroma, nevus, skin tag, pyogenic granuloma, cyst, basal cell carcinoma, and seborrheic keratosis [1,2]. Importantly, Robson et al. [5] reported that $18 \%$ of eccrine porocarcinoma arised from benign eccrine poroma. For these reasons, an eccrine poroma in the facial area requires histological examination, complete excision, and followup.

\section{REFERENCES}

1. Choi YJ, Kim HS, Lee JY, Kim HO, Park YM. Eccrine poroma on the postauricular area: a rare presentation. Ann Dermatol 2013;25:92-4.

2. Moore TO, Orman HL, Orman SK, Helm KF. Poromas of the head and neck. J Am Acad Dermatol 2001;44:48-52.

3. Goldman P, Pinkus H, Rogin JR. Eccrine poroma; tumors exhibiting features of the epidermal sweat duct unit. AMA Arch Derm 1956;74:511-21.

4. Hyman AB, Brownstein MH. Eccrine poroma: an analysis of fortyfive new cases. Dermatologica 1969;138:29-38.

5. Robson A, Greene J, Ansari N, Kim B, Seed PT, McKee PH, et al. Eccrine porocarcinoma (malignant eccrine poroma): a clinicopathologic study of 69 cases. Am J Surg Pathol 2001;25:710-20. 